\title{
Design and Study of Network Service Platform
}

\author{
Gao Siyue ${ }^{1}$ and Cai Quanzhe ${ }^{2}$ \\ ${ }^{1,2}$ Ministry of Physical Education Teaching, Shijiazhuang University of \\ Economics, Shijiazhuang City, China \\ gaosi_yue@163.com
}

\begin{abstract}
There are many problems in the current management of sports venues in China, such as venue service is too rigid, not the public service, leads to the resource waste of venues in your spare time; Venue fewer meets the requirement of training. Some managers' responsibility is consciousness, resulting in slow sports equipment is easily damaged and maintenance and so on. With the rapid development of our country economy, people's health consciousness is more and more strong, our sports venues have already can't adapt to the current situation. The rapid development of modern computer technology and network technology, have created favorable conditions for the network service platform of the development of sports venues, provides an important train of thought for the development of the sports venues of our country. This paper design the development of network service platform system of sports venues, the venue booking system, management system and financial system planning. Hope to improve the service level of venues, meet the exercise needs of the masses, and improve the economic benefit and social benefit.
\end{abstract}

Keywords: networks; services platform; design; physical education

\section{Introduction}

With the rapid development of economy and sports industry, more and more people attention on the sports stadiums as an important part of the sports industry. Therefore, the construction of the sports facilities invested a lot of money. The rapid development of large stadiums in the quantity and quality of career development of sports provides important material foundation and security, not only for the rapid development of China's athletics provides a hardware conditions, and efforts to open free and paid services provided to the community, and promote to carry out a mass sports, becoming higher economic "growth point" sports body industry, but also for the reform and development of the next major sports venues, has accumulated a wealth of experience. However, due to the construction of major sports venues themselves have high standards, a large amount of investment, the function is more complete and modern equipment, after the game management complexity and high maintenance costs, if operating properly, it's high operating and maintenance costs will inevitably become the government's heavy burden.

For a long time, because a variety of factors economy, ideas, management, institutional and other sports venues of operation, management level hysteresis, resulting in major sports venues and facilities for the community long-term closure, single function, low efficiency. Most of these problems are due to essentially have a very poor management led to the venue, that is because of our overall business management battalion level venue is still in its infancy, China's major sports venues in terms of construction or from the management and operation of all there are many drawbacks. Therefore, the operation and management of large stadiums will be an important topic in the field of sports industry in a letter to be studied. 
With the continuous optimization of modern network environments, building a network of digital venues has become the development trend of sports venues. For example: In the United States, major sports venues are very focused on network marketing, major sports venues have their own website, through the Internet publishing business information, timely release of venue information, advertising, so you can costeffectively meet consumer who needs [1]. Internet marketing has traditional marketing can not match advantage, the ability to text description of the product marketing activities, promotions, customer opinion surveys, advertising, public relations, customer service, etc. through, sound, pictures and visual means of organic integrated flood, one on one communication, to really pursue a comprehensive integrated marketing effect [2]. Because network marketing has many advantages, it appeared to the traditional marketing methods will constitute a powerful impact, and thus want their business major sports venues must attach importance to the sustainable development of the construction of the network service platforms [3-4]. Therefore, the establishment of a network service platform stadiums also imperative. Based on the sports enthusiasts some provinces of site visits, research and found that almost all sports fans go sports stadiums are different levels of experience to go to the venue sports and fitness, but found the venue at full strength, the venue had to wait in line; Although the site or vacant, but it can not keep abreast of information and wasted space vacant sporting opportunities. For the above, we confirm that the development of the network platform to take care of needs of users' convenience and information instantly query. Based on B/S mode can be done as long as there is a platform where you can use the network, reflecting the strong convenience, so we used the $\mathrm{B} / \mathrm{S}$ architecture system.

\section{Design Stadiums Network Service Platform}

\subsection{Stadiums Network Service Platform Design Goals}

After combining stadiums network service platform with its own characteristics, and use of the system user-specific information such as the design of the system should meet the target the following areas:

2.1.1. The system should be designed to meet the operational requirements of safety: At the time of system design, we must fully consider the security features of the system, to ensure that the system user's own information not be disclosed, to ensure user login security.

2.1.2. The system should be designed to meet the object-oriented design: Objectoriented programming ideas that can largely reduce the redundancy program code can reduce the complexity of the corresponding program. Object-oriented programming ideas that can make a programmer in the form of objects to interpret the code, the program is not only conducive to the early work of concurrency and, for the latter part of the program maintenance work is also a great help.

2.1.3. The system should be designed to meet the modular design concept: Modular design, you can make the program function corresponding to the module form, when the system design is more flexible in the late modification of the system is more convenient and flexible. Especially after use in the expansion program, this is more convenient and flexible. 
2.1.4. Design of the system should be managed as the goal: A system with manageability in the design and development of the system is more convenient and flexible, and fault analysis during system operation, maintenance, and determination brought convenience is not to be underestimated.

2.1.5. Design of the system should be easy to use for the target system: Design of the system must be easy to use, so the design phase of the system in order to ease the system to target. The design of the platform uses the $\mathrm{B} / \mathrm{S}$ structure of network database and related knowledge, as shown in Figure 1.

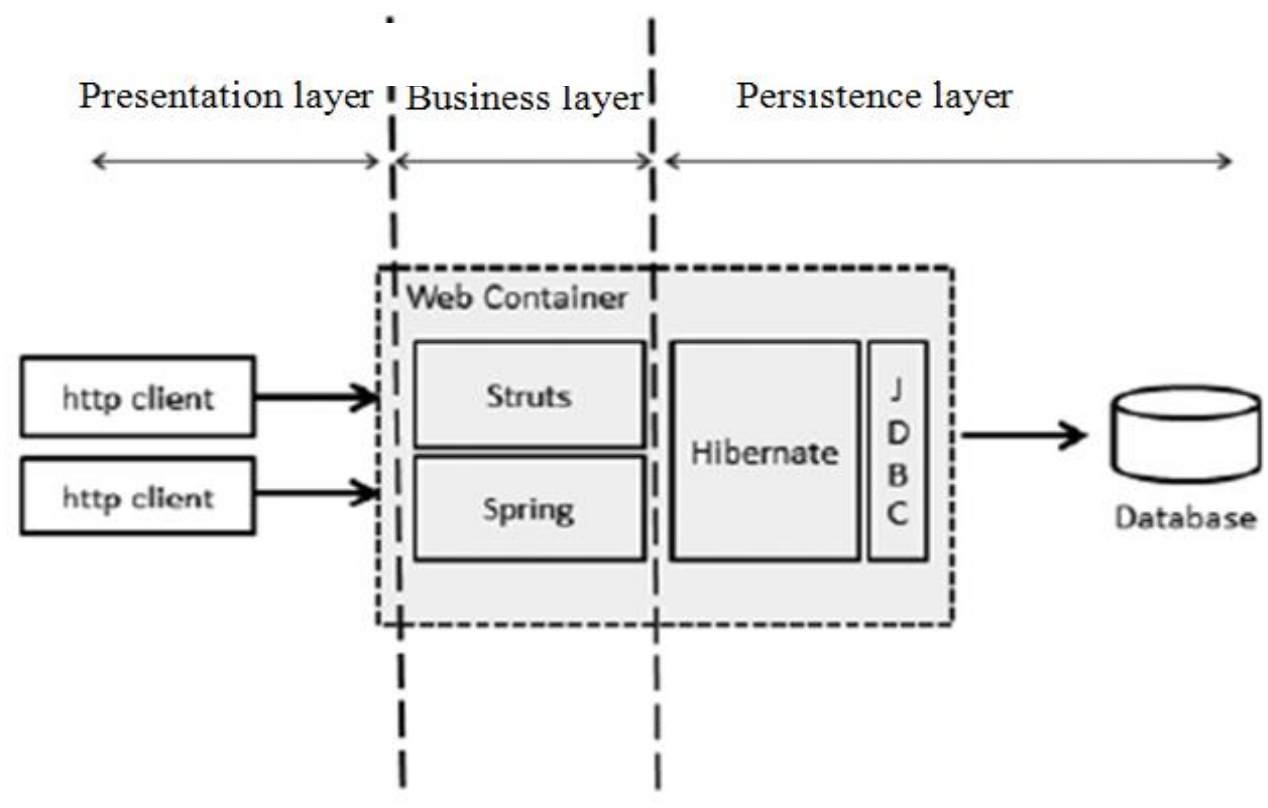

Figure 1. Platform Structure of Network Database

\subsection{Stadiums Network Service Platform Architecture Design}

Platform uses B/S (Browser/Server) architecture system three-tier software architecture, the first layer is that the performance of the foreground layer, the second layer is the business logic layer, and the last is the data management. All users submit a request to the server through a browser, the server will analyze these requests, some relationship with the data, you need to interact with the data server after the request has been processed, and the results are returned to the client browser (Figure 2).

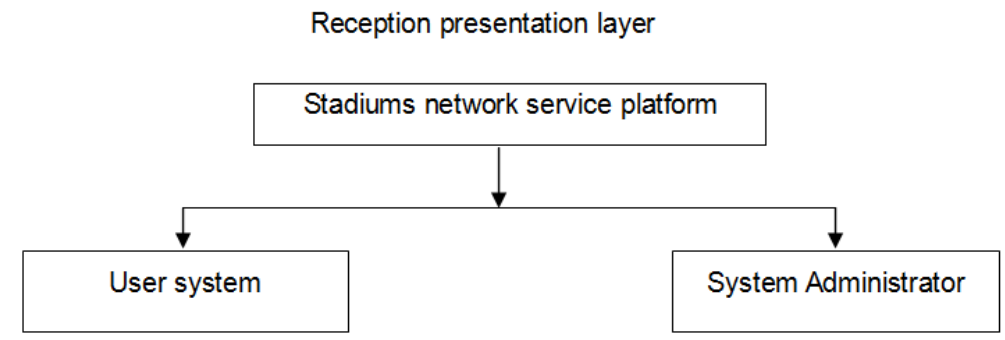




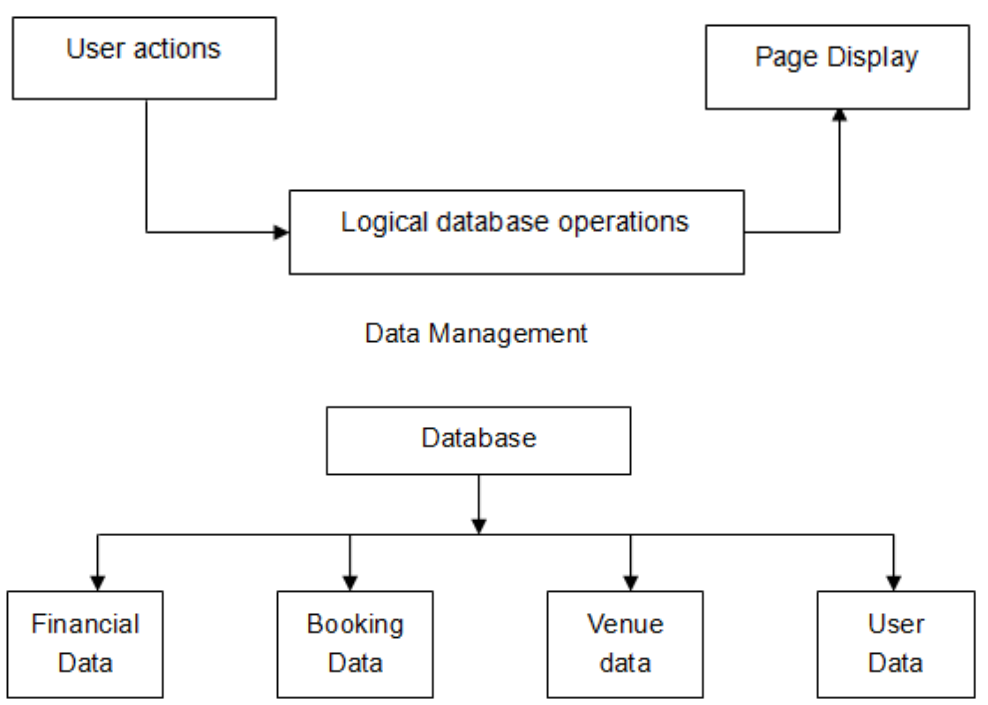

Figure 2. Overall Platform Architecture System Diagram

Platform architecture system features:

(1) User operation quick and easy and convenient: the client that can query the information they need and complete related tasks through a browser, the daily required platform database maintenance, system upgrades and other work functions are only on the server side [5]. WEB browser users do not need to install any client software to browse the Web; but usually regardless of any time, any place, just one Internet browser, login page platform that enables browsing, queries, booking various sports venue information.

(2) a database query and management of intelligence: the technical level in the system for different users grading classification management, so that different levels of users have different platform module browse, query, permission entry, modify, print and other functions. Thus, stadiums network service management platform can play a convenient and efficient remote services, management functions, and different from simple web browsing, multi-directional capabilities to meet stadiums network management, information, intelligence requirements.

(3) A better user experience: the platform can change according to the user operation information to achieve partial page updates without refreshing the whole page, there is no need to wait, the information submitted by the user can get immediate feedback, allowing users to get better experience effect.

\subsection{Stadiums Network Service Platform Module Design}

Stadiums need to achieve a variety of network services platform functionality. From the foregoing, in stadiums network service platforms need to be designed mainly from two aspects, namely the system functional modules and systems foreground backstage functional modules. The following functional structure of each subsystem design analysis platform.

2.3.1. Stadiums Reservation System: System foreground, namely stadiums reservation system, it can be operated viewing system interface. User login system website, you can check some of the public information resources and by appointment venue users only 
need to register an account on a number of venues to understand the system can provide the front desk, and in line with their specific requirements venues terms of time reservations. Specific functions as follows (Figure 3):

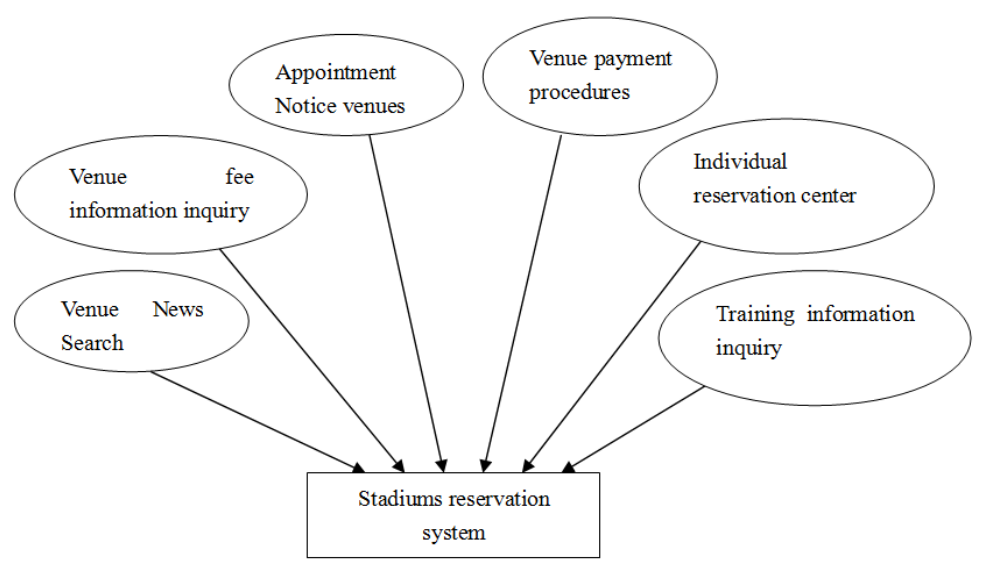

Figure 3. Stadiums Reservation System

(1) Venues News queries. Users can keep abreast of the latest news various sports venues.

(2) Venues charging information query functions. Users can keep abreast of the venue opening hours, fees, precautions and other information.

(3) Venues appointment notes feature. Telling the user how to book various venues in order to successfully booked for their own venue.

(4) Venues payment processes. Users follow the payment method, payment steps to prevent the loss of money.

(5) Personal reservation center. Users can access their personal information, booking conditions, consumer records, booking changes, etc.

(6) Training information queries. Users can promptly know the venue opened training situation, to select the item of interest.

2.3.2. Asset Management System; At this stage the majority of the stadium is owned by the state investment in the construction, the establishment of a network service platform we need the government entrusted to manage business operations. Therefore, we will asset management system is divided into two parts: the business management system, and government administrators systems. While the government administrators realize related management functions through the system, can also be achieved stadiums lease management functions. Businesses entering the account number assigned by the administrator merchant management system related operations. The specific features are as follows (Figure 4): 


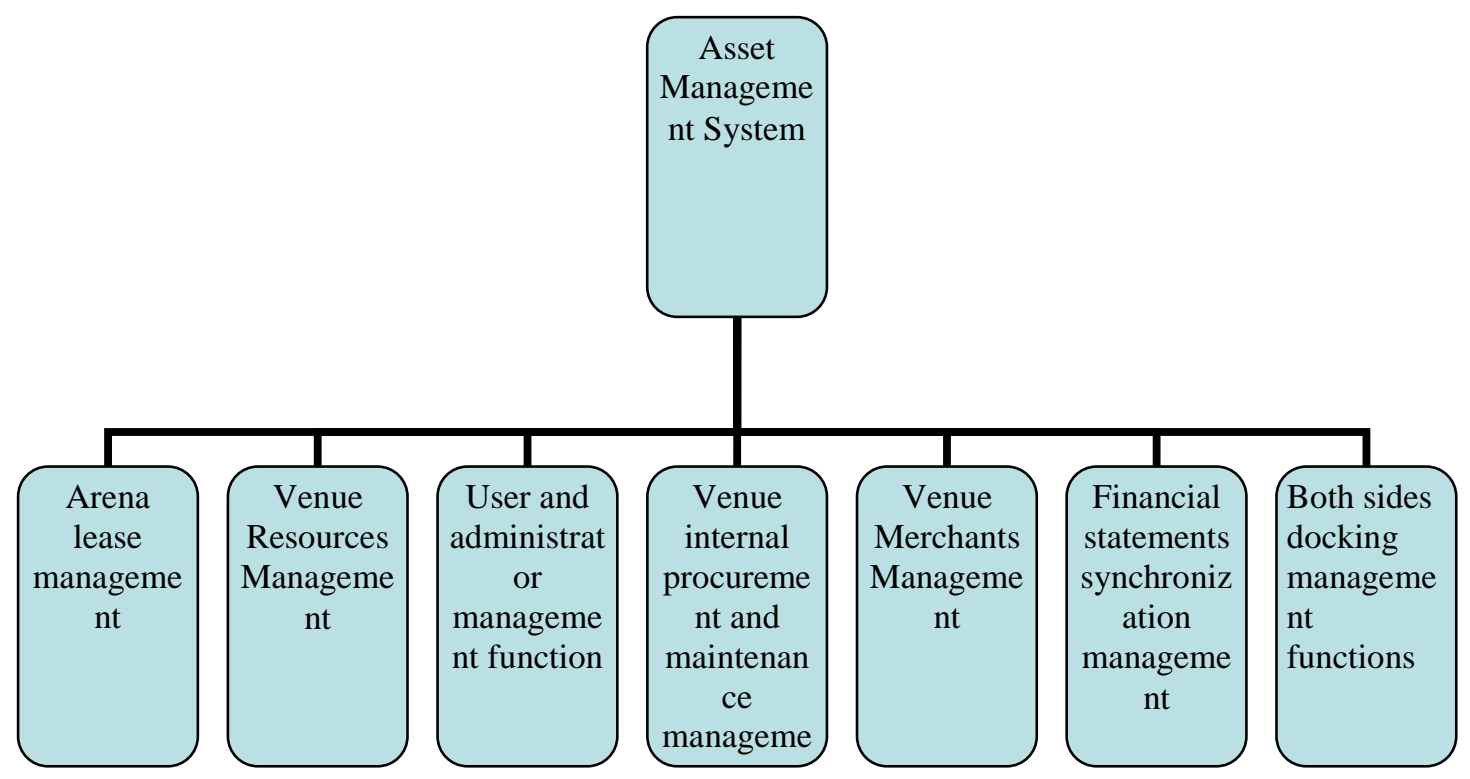

Figure 4. Asset Management System

2.3.3. Venue Management System: Venue management system is a system administrator various venues used. Through this system, the venue for this venue administrators can pre-conditions, consumer status, financial status, etc. for effective management. Specific functions as follows (Figure 5):

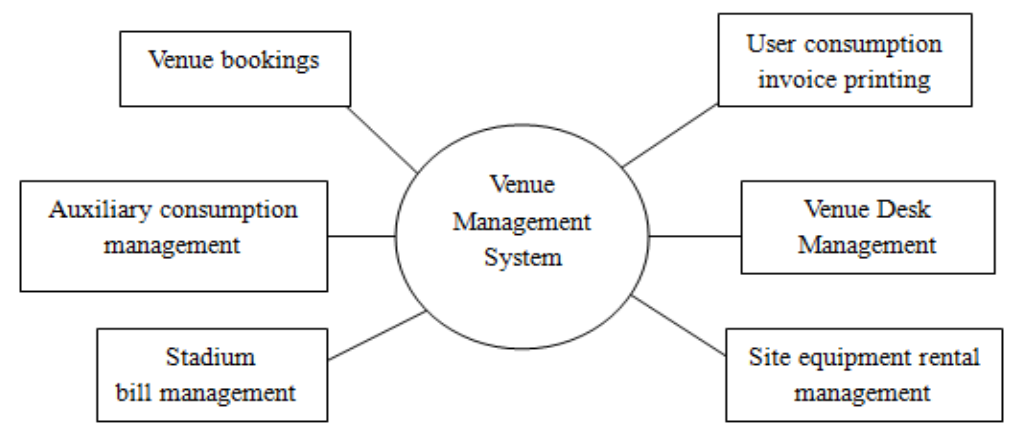

Figure 5. Venue Management System

2.3.4. Financial accounting management information system: The system of financial proprietary systems used by financial administrator can be financial settlement, bill printing, exporting financial statements, financial docking and other functions [6]. Specific functions as follows (Figure 6):

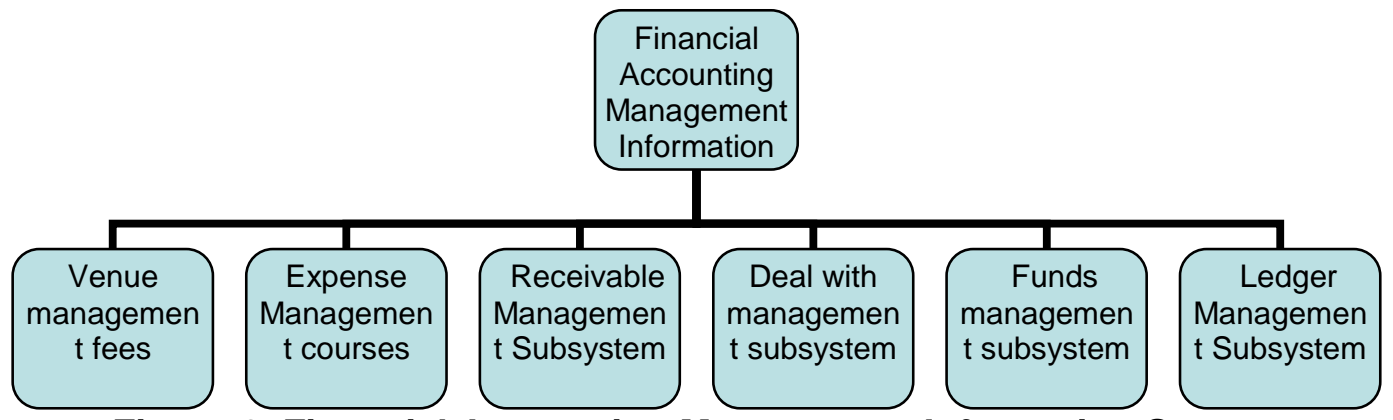

Figure 6. Financial Accounting Management Information System 
(1) Venues charge of project management capabilities.

(2) Training costs query management function.

(3) Receivable management subsystem: including one for checkout, receiving orders and other information were various sports venues receivable entry, query, maintenance, and generate reports and other functions (Figure 7).

Binding must be provided when using the user name and password. SASL authentication API for ldap_sasl_bind(), it will need to provide authentication mechanism and user credentials. The common API for ldap_bind(), it can be verified method parameter to specify alternative to one of the first two certification. All you need to provide either authentication in binding the user's DN and authentication credentials.

ld=ldap_init(“localhost",366);

rc=ldap_simple_bind_s(ld, "cn=root", "root");

If(rc!=ldap_success)

\{fprintf(stderr, “error:ldap_simple_bind_s[\%s] $\backslash n$ ”,ldap_err2string(rc));

$\left.\operatorname{exit}(1)^{\prime}\right\}$

rc=ldap_unbind_s(ld); $/ *$ Used with a binding directory solution and close the connection */

msgid=ldap_search(ld, “o=sample", ldap_scope_subtree, “objectclass=*”, attrs,0);

if (rc!=ldap_success)

$\{$ fprintf(stderr,"error:ldap_unbind_s[\%s] $\mid$ n",ldap_err2stromg(rc))'

$\operatorname{Exit}(1) ;\}\}$

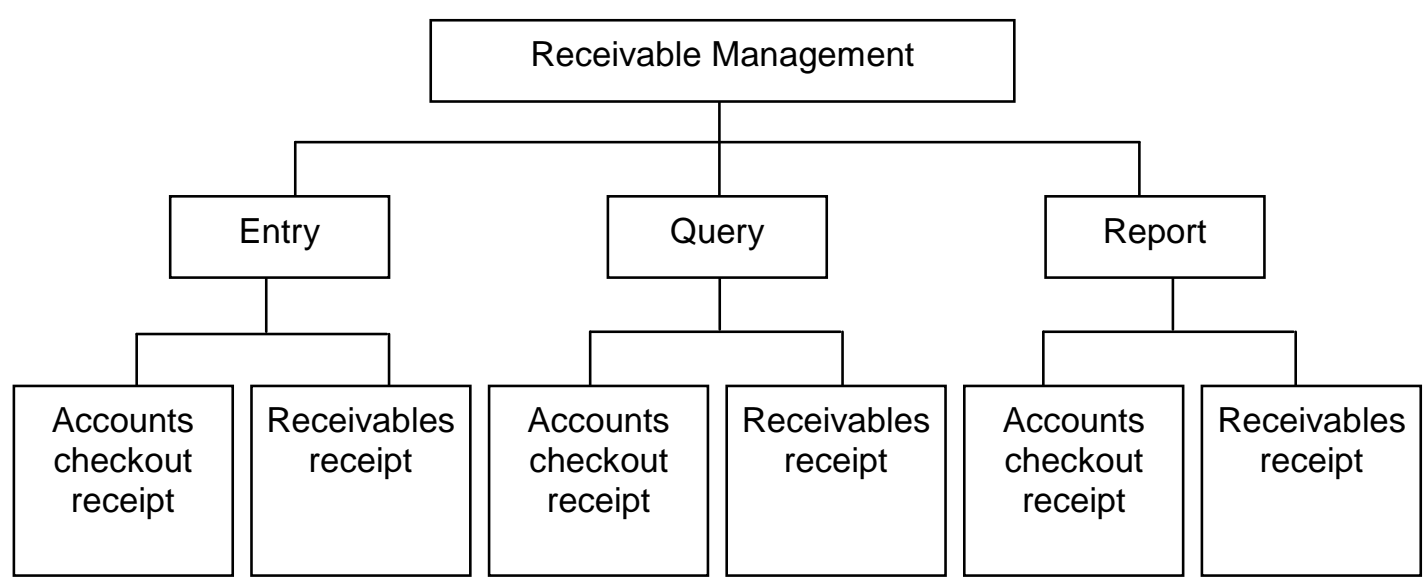

Figure 7. Receivables Management Subsystem

(4) Cope management subsystem: Including the various sports venues to meet the billing statements, payment orders and other information entry, query, maintenance, and generate reports and other functions (Figure 8). 


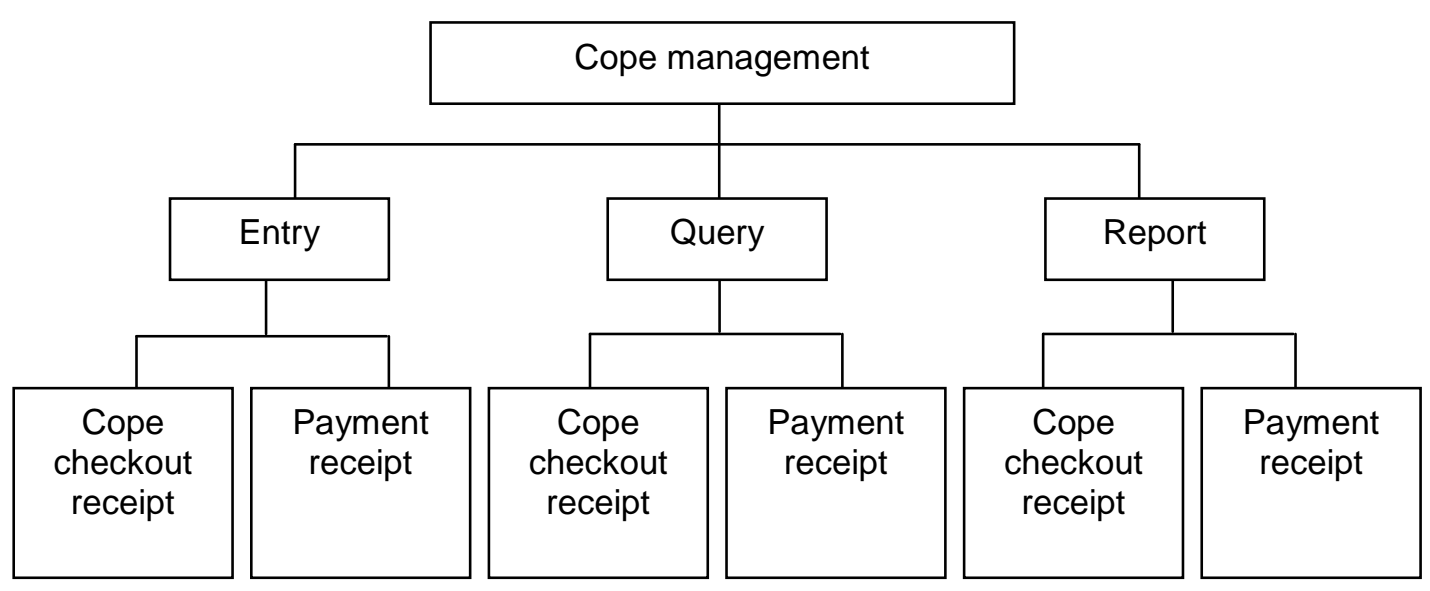

Figure 8. Cope Management Subsystem

(5) Fund management subsystem: including the various stadiums cash cashier, bank teller and other information entry, inquiry, maintenance and reporting functions.

(6) Ledger management subsystem: including entry and maintenance of the venues financial information generated daily journal, ledger and general ledger functions.

2.3.5. User Management System: User management system is mainly produced for Member Center administrator operating system; users can realize the members, trainees of various management services. Specific functions are as follows:

(1) Members do card services.

(2) Members authorized management functions.

(3) Member recharges management functions.

(4) Member permission settings function.

(5) Trainees management capabilities.

The client before can connect to the server is initialized management services environment, set up the management services address and port, the management services protocol version, management services operations timeouts and ceiling returned items, etc.

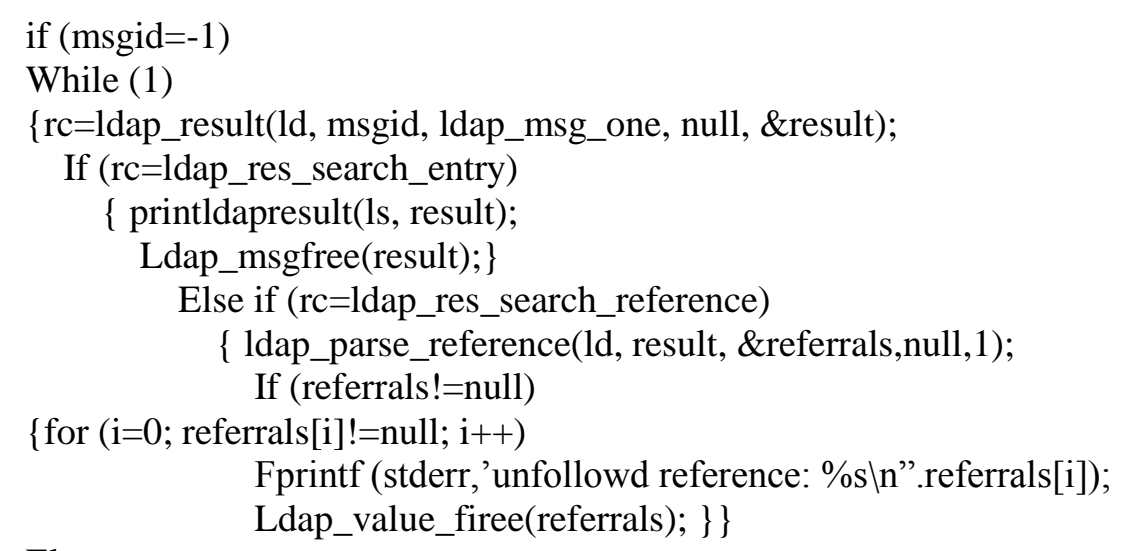

Else

Break; 
2.3.6. Advertising management system:Advertising system is mainly window outreach services across the network platform, the timely release of information can be posted on a public information platform for venues reservation center. Specific functions are as follows:

(1) Advertising publishing news and other timely information.

(2) Venues, departments, businesses and other published information approval function.

(3) Publish training courses and management information.

(4) Trainees information entry, payment functions

\section{The Design Principles of Sports Venues Web Services Platform}

\subsection{Platform Page Design}

Web page is a facade stadiums network service platform, is a strong artistic work if the page layout is unreasonable, key information is not visible, will greatly affect the user access to the site, people lose interest in browsing. Therefore, the layout of the site should try to make the theme clear, clear structure, so that the user can feel a click on the web site's featured content.

With the rapid web production technology, web elements of the increasingly rich is not only a variety of text and images data, voice, video, data and interactive effects of various programming languages has become a major component of the page, vivid and complex web allows web designers need to have a more comprehensive web production technology.

3.1.1. Text Layout Design: As we all know, page text layout design for the overall effect of the page has a very significant impact. Like traditional newspapers and magazines, we will be seen as a web newspaper, a magazine for publishing word processing, for different needs, there may need to use some special text layout skills. Text is an important carrier of information, the overall design of the impact of its font, size, color, and arrangement of pages greatly [7]. Text layout and design of sports stadiums network service platform, its style and content to match the characteristics of the entire site must not conflict with each other breach. For example: a sports stadium in the introduction page, font type, we should arrange some more, make this forum colorful, a little active; important notice in the release, we should control the font type in one to two kinds, to make it layout and elegant, there is a sense of stability. In addition, the text in the picture pages have arrangements to take into account global factors, not conflicting visual. Otherwise, the picture confuses easily because confusion visual order. And the whole meaning and atmosphere works are likely to be destroyed.

\subsubsection{Picture of Layout Design}

In order to make a good website design, so attractive, so that respondents liked, not only to make each section of content rich web pages, unique perspective, profound meaning, highly informative and inspiring, but also with a picture with the good content, rather than the web to dress nice too bright, quiet yet lively being, giving the joy of beauty. For example: Venues on the page to insert photos inside some venues, services, facilities, and will be more beneficial to the user to choose their own venues. However, we have to control the number of page images, the accuracy and size, let Web Images really play both information and dress up web hosting, web beautifying effect.

3.1.3. Multimedia Layout Design: The main page of the multimedia elements including audio, and animation, it can give the user a more intuitive information experience, but 
because of the multimedia elements are often larger capacity, network bandwidth users have certain requirements, so designers to consider access to web pages speed, on the page and not a lot of use, generally as a Web page in the CBD.

3.1.4. Color Design: Web Design Color is an important visual element, accounted for a large proportion, because the color is the emotional expression of the public, with good color, to design a harmonious work. Impressive site, colors are very successful deployment. For example, Coca-cola red, Pepsi blue, orange Keshi gives the harmonious visual experience, the success of these sites in their colors with impressive [8]. Avoid using pure tones without chiaroscuro change, and the best intermediate auxiliary colors set off, so that it can achieve the effect of making the color balance. Color pages are not biased towards one party, such as the middle of the page if there are chunks of color gamut, it must be surrounded by a small auxiliary gamut, color matching so that we can complement each other, avoiding the overall effect of weightlessness.

\subsection{The Security Measures Implemented Website}

Design, build databases of websites are built on top of the operating system, secure operating system for the development of the site and provides information systems to produce, scheduling control, passing a good platform for processing, only the establishment of a secure server operating system in order to guarantee secure site [9]. Any system are caused by human design, can not be perfect, vulnerabilities, risks can not always be avoided, so we guard against mission is to improve the system, reducing defects and fix vulnerabilities.

Platform in terms of data encryption using the "SHA1" that secure hash algorithm [10]. Simply put, the platform will be members of the user's password after SHA1 calculation generates a $2^{\wedge} 160$ do not have any sense of the string, the string theory is absolutely impossible to duplicate. Then, the platform will replace the string set by the user passwords are stored in the back-end database server, as credentials to verify the user's identity, and the letter string data irreversible. Even if someone invaded server to view user information to the database, but also from a meaningless string of letters can not identify the original password data users to fully protect user data security.

In addition, the setting and the timely replacement of the system administrator password, prohibit the use of the same administrator account password on multiple servers. For application on the server should use different passwords, to improve system account security level. Finally, should the system files, log timely backups, including remote backup and client management computer backup.

\section{Conclusion}

With the people's demand for increasing physical fitness, traditional stadiums service management model has been unable to meet the people's demand for sports and fitness services. In an era of rapid development of Internet technology, stadiums network service management model will gradually become a trend. Therefore, the design of a new situation to meet the needs of fitness gyms reservation system is very necessary and important. By design a stadium network service management platform that allows users to get more convenient, more information and better services, but also allows venue managers service management more scientific, efficient, standardized and transparent.

\section{References}

[1] W. W. Cooper, J. L. Ruiz and I. Sirvent, Euro. J. of Oper. Res., vol. 2, no. 195, (2009).

[2] G. Y. Miao, G. Y. Zhu and S. Q. Jiang, "The Demo: A Real-Time Score Detection and Recognition Approach in Broadcast Basketball Sports Video", ICME, vol. 46, (2007). 
[3] H. Shan and L. Chaofeng, "Registered online booking system development and application of digital medical China", vol. 9, (2012), pp. 70-71.

[4] S. Ye, C. Chen and F. Hu, "World J. of Engng. and Technol. Educ.", vol. 11, no. 3, (2013), pp. 260-266.

[5] Y. Shimokochi, SY. Lee, S. J. Shultz and R. J. Schmitz, "J. of Athl. Trai.", vol. 44, no. 1, (2009), pp. 3338.

[6] T. Donghui and Y. Feng, "Phys. Inst. of Shanxi”, Norm. Uni., vol. 6, (2011), pp. 42-45.

[7] Y. Jia and S. Quansheng, "Chengdu Inst. of Phys. Edu.”, vol. 4, (2010), pp. 45-47.

[8] G. B. Wilkerson, J. Todd Bullard and D. W. Bartal, "J. of Athl. Trai.", vol. 45, no. 1, (2010), pp. 67-74.

[9] C. Yanyan, "Design and Implementation of College Sports Network Teaching Platform", Beijing: University of Posts and Telecommunications, (2010).

[10] E. Doran, “The Know. Engi. Rev.", vol. 12, no. 3, (2007), pp. 309-314. 
International Journal of Signal Processing, Image Processing and Pattern Recognition Vol.9, No.2 (2016) 